\title{
Preliminary design of electromechanical actuators with Modelica
}

\author{
Marc Budinger (*), Jonathan \\ Liscouet $(*)$ \\ Université de Toulouse, IN- \\ SA/UPS, Laboratoire de Génie \\ Mécanique de Toulouse \\ Toulouse, 31077, France \\ marc.budinger@insa- \\ toulouse.fr
}

\author{
Yvan Lefevre(**), Julien \\ Fontchastagner(**) and Abde- \\ nour Abdelli(**) \\ Université de Toulouse, \\ INPT/CNRS, Laboratoire Plasma \\ et Conversion d'Energie, Tou- \\ louse, 31071, France \\ Yvan.Lefevre@laplace.univ- \\ tlse.fr
}

\author{
Loig Allain(***) \\ LMS-Imagine \\ La Cité Internationnale \\ 84 quai Charles de Gaulle \\ 69006 LYON \\ loig.allain@1msintl.com
}

\begin{abstract}
This article deals with a methodology for a computer-aided design of electromechanical actuators from the preliminary design of components to the detail design of the electrical motor. The developed library of components for the simulation takes advantage of the non-causal and object oriented characteristics of the Modelica language. The capabilities of the Modelica language and the LMS.Imagine.Lab AMESim or Dymola Platforms are strongly used in order to build a fully integrated process to design and size the different component of the final actuator. The proposed approach is illustrated with the sizing of a flight control actuator.
\end{abstract}

Keywords: preliminary design, inverse simulation, scaling laws, electromechanical actuator, brushless motor

\section{Introduction}

Thanks to the development of powers electronics and permanent magnets, electromechanical actuators are very promising with respect to, e.g. automatic operating mode, power management, reliability, maintainability. For this reason, it can be very interesting to replace current actuators based on another technology less promising in these fields (e.g. hydraulic) with electromechanical actuators. A good illustration of this tendency is the research effort towards the "more electric aircraft" in aeronautics [1]. An electromechanical actuation system is very complex to design and to optimize, especially because of its multidisciplinary characteristic [2]. This paper presents a new methodology to help the engineer from the preliminary to the detailed design of electromechanical actuators. Modelica coded libraries used here are especially to encompass 2 steps in the $\mathrm{V}$ design cycle (Figure 1) :

- The power sizing (part 2) which aims at sizing and specify the various components of the operating system in order to meet the specification requirements (on nominal points or on mission profile) in terms of effort and speed (and therefore power).

- The detailed design of components (part 4), brushless motor here, which allows the designers to obtain fine sizing of components in order to enable the fabrication and more accurate simulations.

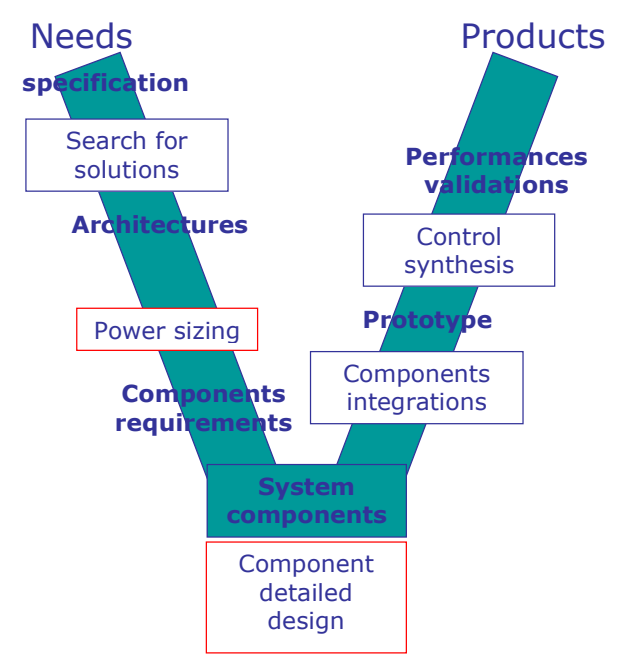

Figure 1: V design cycle

The libraries presented in this paper are illustrated in part 3 and 5 by the design a flight control actuator (see Figure 2) from global specifications to the fine sizing of the brushless motor. 


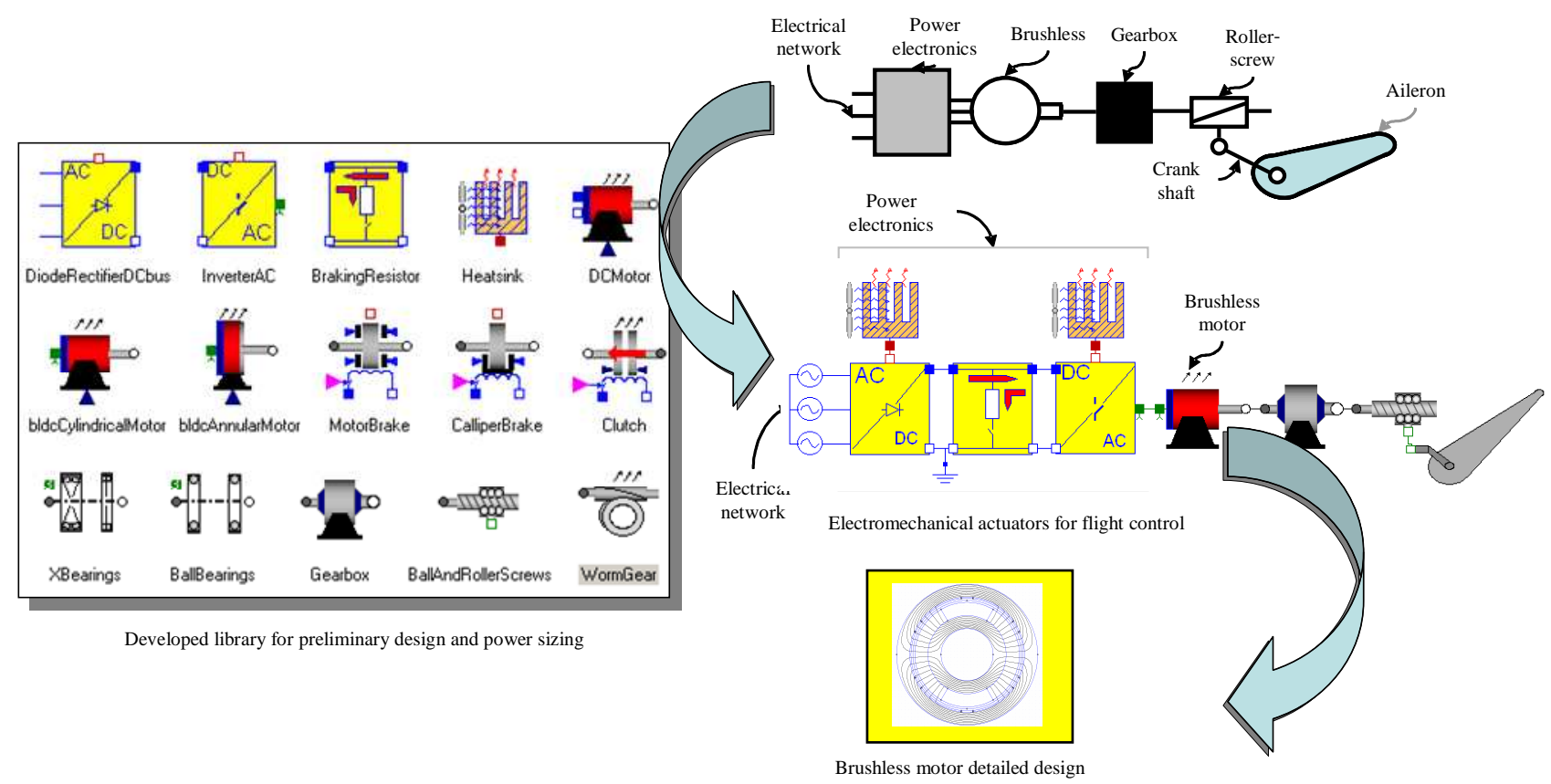

Figure 2: Rapid design of an electromechanical actuator for a primary flight control surface of an aircraft

\section{Preliminary design library for components specifications}

\section{1 - Sizing wave}

As indicated in the previous part, the power sizing aims at determining the correct size of the devices in order to comply with the mission profile of effort and speed. Then the general methodology can be expressed as follows (see Figure 3):

- Based on the load and associated mission profile, effort and speed of each component are calculated following the entire actuation chain.

- Every component is sized such that it covers the mission profile curve established between effort and speed and requirements on other sizing parameters are satisfied, e.g. the RMS torque for an electric motor.

The simulations require many parameters that are known as "simulation parameters" (eg: Inertia, stiffness, thermal time constant, etc). They feed directly the equations that are solved by the equation solver.

Designers want to scan a large range of solutions quickly without searching for these very numerous "simulation parameters". It is preferable for them to work directly on a small number of "definition parameters" that characterize the components they use in a more technological way (e.g., Torque, speed, speed reducing ratio, etc.).

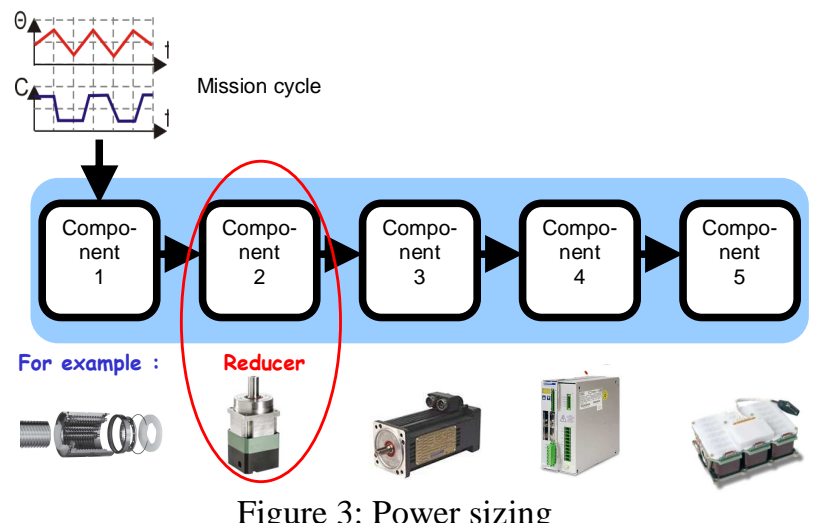

The simulations aim at confirming the selection of the components and carrying out a comparison analysis between different architectures. The simulation should allow the assessment of "sizing parameters" (eg: RMS torque for electric motors, RMC torque for speed reducers, etc) and of "comparison parameters" (e.g., mass of the component, etc).

Traditionally, the designers look into catalogues of manufacturing companies to get simulation parameters and make comparison between solutions. It requires repeated revisions of the design and of course, 
a lot of work. To avoid this time consuming iterations, some simulation software are equipped with large databases of full ranges of components [3-5]. For our preliminary design library, it has been decided to develop models of the components on the basis of scaling laws in order to avoid the huge tasks of databases creation and maintenance. These transparent scaling laws provide users with the relationships between the definition parameters with simulation, sizing and comparison parameters.

For example, these quantities are for mechanical speed reducers (epicyclic gearing for example):

- Definition parameters: torque output, gear ratio, desired service life;

- Simulation parameters: equivalent inertia, efficiency, parameters necessary for evaluation of service life;

- Comparison parameters: mass, volume;

- Sizing parameters: maximum torque and speed during a mission cycle, equivalent torque in fatigue.

\section{2 - Inverse simulation with Modelica}

The methodology described here requires the evaluation of the power variables of all the components for an imposed mission profile [6]. Traditional system simulation software such as Simulink does not achieve this kind of simulation using standard models and by making simple assembly of components. The simulation language Modelica [7, 8] is noncausal and does not impose a direction to the variables. In this way, a variable can be either the input or the output depending on the engineer needs.

\section{3 - Scaling laws}

The scaling laws, also called similarity laws, allow the study of the effect of varying representative parameters of a given system. They are used in different domains as microsystems [9], mechanics [10], hydraulics, fluid mechanics to compare different actuator technologies [11], to adapt the dimensions of a mock-up in fluid dynamics, to size mechanic, hydraulic or electric systems, to develop and rationalize product families or to evaluate costs. This article uses the notation proposed by M. Jufer in [12] for scaling laws calculation. The scaling ratio of a given parameter is calculated as

$$
l^{*}=l^{\prime} / l
$$

With $l$, the parameter of the component taken as reference and $l$ ', the parameter of the studied component.

A homothetic scaling of all the geometrical dimensions leads to link them all to their reference value by a single ratio $l^{*}$. Models are developed only for components with a geometrical similitude. In this way, the evolution of a volume $V$ of a cylinder in case of an identical evolution for all geometrical dimensions is

$$
V^{*}=l^{* 3}
$$

This last result remains valid for any other geometry. In the same way, it is possible to calculate the evolution of the mass $M$ and rotating inertia $J$ as function of the dimension $l$ :

$$
\begin{aligned}
M^{*} & =l^{* 3} \\
J^{*} & =l^{* 5}
\end{aligned}
$$

During scale change of components (e.g. motor, reducer, mechanism) some constraints must remain constant. These sizing constraints ensure an adequate use and life time for the components. For mechanical components, the constraints in the materials are limited by the elastic or fatigue limits. The use of scaling laws allows the direct determination of the simulation parameters (such as inertia) and comparison (e.g. with respect to mass) from the definition parameters (e.g., the torque). Thus, instead of using heavy databases that are difficult to build, only one reference component for each type of technology is required.

\section{4 - Operating areas and sizing laws}

During the simulation, it is necessary to verify the behavior of different components along the mission cycle to prevent their degradation. Generally, two types of operational limits should be distinguished.

The first limit is due to a rapid deterioration of the component: this limit corresponds to the surface operating areas which are expressed in term of energy quantities such as effort and speed. For speed reducers, this corresponds to the material's elastic limits, followed by the absolute torque that the reducer can withstand and that is limited by the maximum mechanical constraint that its weakest point can withstand. It is possible to develop models to determine torque and speed limits with the help of scaling laws. The second type of operational limits corresponds to the gradual deterioration caused by damage accumulations which limit a component's service life or reliability. For speed reducers, this corresponds to the material's fatigue limits. In practice, the fatigue torque and the mean speed of a reducer are calculated to ensure the desired service life and reliability.

\section{5 -Software implementation}

The joint use of inverse simulation, scaling laws and calculation of sizing quantities has been implemented by the authors in a Modelica library for pre- 
liminary design of electromechanical actuators. Figure 1 illustrates the nature of the components that are frequently used in electromechanical actuation systems. The assembly of these components can help to model a large number of architectures. The next part of the article illustrates their use.

These Modelica blocks or components were coded in a similar way to that illustrated by the example of the reducer in Figure 4. The parameters setting interface, Figure 4 (a), presents parameters to be set by the user. The aim of their minimal number is to facilitate the manual use, exploration or optimization during the preliminary design phases. The example of the reducer requires:

- A reference of an industrial component that is a feature of a product range or of a technology which contains in a record all reference parameters.

- The definition parameters, here the torque and the gear ratio of the reducer: all the simulation parameters and the comparison parameters are calculated from theses quantities and from parameters of the reference component.

- The service life of the component: the component's reliability is calculated assuming that the mission profile of the mission to be simulated is repeated during the service life.

Figure 4 (b) shows the internal structure of the component, which is representative of the notions developed previously in the article and includes:

1. A physical model, which allows inverse simulation, making it possible to inversely determine for each component the effort and speed of the mission profile. It allows as well the calculation of the characteristic dynamic quantities of degradation or of physical limitations.

2. Scaling laws, which calculate all the parameters necessary for simulation on the basis of parameters provided by the user.

3. Validation of the use of the component in the authorized functioning area. It verifies that the definition parameters can meet the mission profile.

4. Calculation of the cumulated damages. It takes into account the characteristic of fatigue.

5. Reliability calculation for the duration (number of hours) specified in the user interface. It allows the user to size the component accordingly to a given reliability.

6. Calculation of continuous quantities that are equivalent to the mission profile for a typical reliability of $90 \%$. It helps the user to specify the sizing quantities adapted to the mission profile.

(a)

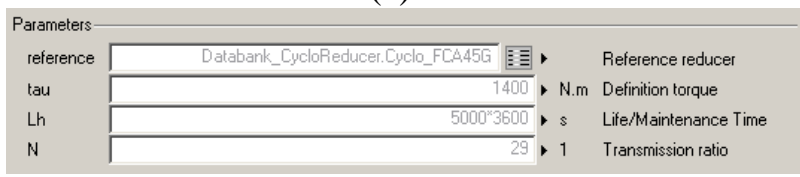

(b)

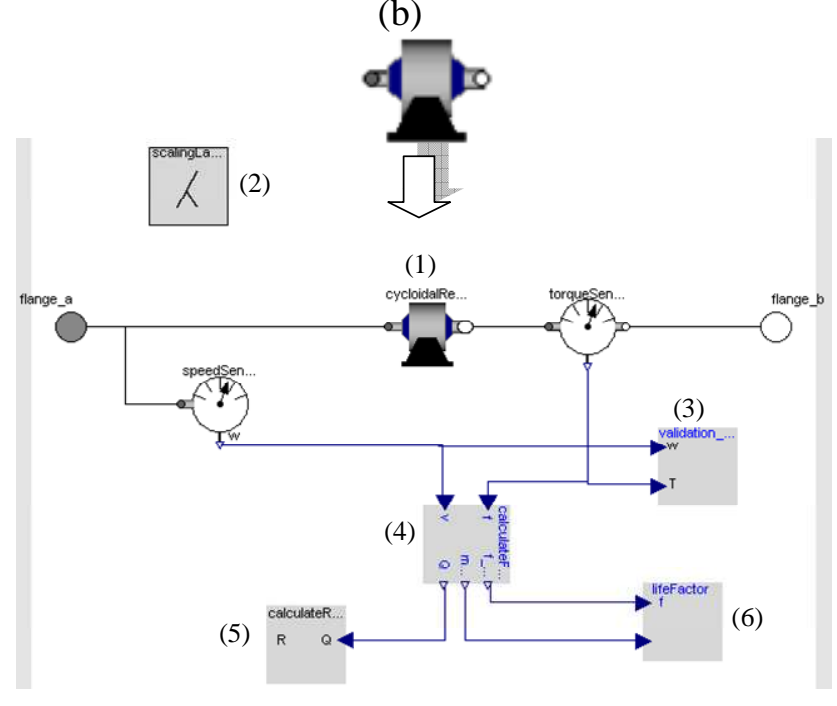

Figure 4: Parameters setting interface and inside structure of a component

\section{Preliminary design of an aileron actuator}

\section{1 -Case study presentation}

For this case study, an electromechanical actuator equivalent to the current hydraulic one is developed. In this way, the kinematics of the aileron and its actuator remains identical (i.e., use of a crank shaft and pivots and actuator stroke of $4 \mathrm{~cm}$ ). In the current configuration, two actuators are connected in parallel to the load in an active-damping mode, where one acts on the aileron and the other is damping. However, for simplification purposes the de-clutching and damping aspects are not addressed in this study.

In order to give a frame to the design, the choice of the reduction ratios of the roller-screw and speed reducer is driven by an imposed electrical motor speed. First, the pitch of the roller-screw is minimized $(5 \mathrm{~mm} / \mathrm{rev})$, thus the mass of the speed reducer is minimized. The observation of manufacturer catalogues [13] shows that $10000 \mathrm{rpm}$ corresponds to the maximum speed of the motors characterized by the max power required by the application $(\sim 110$ $\mathrm{W})$. Accordingly, the speed reducer ratio is adjusted 
to match a motor speed of $10000 \mathrm{rpm}$, in order to minimize the motor output torque and thus its mass. The model of the load used for this study consists of an equivalent aileron moment of inertia of $1 \mathrm{kgm} 2$, with a crankshaft of $45 \mathrm{~mm}$. The effort from the antagonist hydraulic actuator is caused by the relatively low windage friction (about $107 \mathrm{~N} /(\mathrm{m} / \mathrm{s})^{2}$ ) and inertia of the hydraulic cylinder. It does not impact the power sizing notably and is therefore neglected. In the same way, the low frictions in the pivots of the load kinematics are not taken into account. Finally, the aerodynamic efforts are given along with the mission profile as a function of time.

On the one hand, the mechanical components are sized with respect to the maximum effort and speed, as well as the fatigue cumulated over their specified lifetime. On the other hand, the motor is sized with respect to the maximum effort and speed, as well as thermal constraints (e.g., temperature, RMS torque). As a consequence, two mission profiles are used for sizing: One representative of maximum effort and speed and another representative of the thermal constraints. Figure 5 illustrates these two mission profiles propagated at the actuator output (pivot between the actuator and crank shaft) in the force-speed power plan.

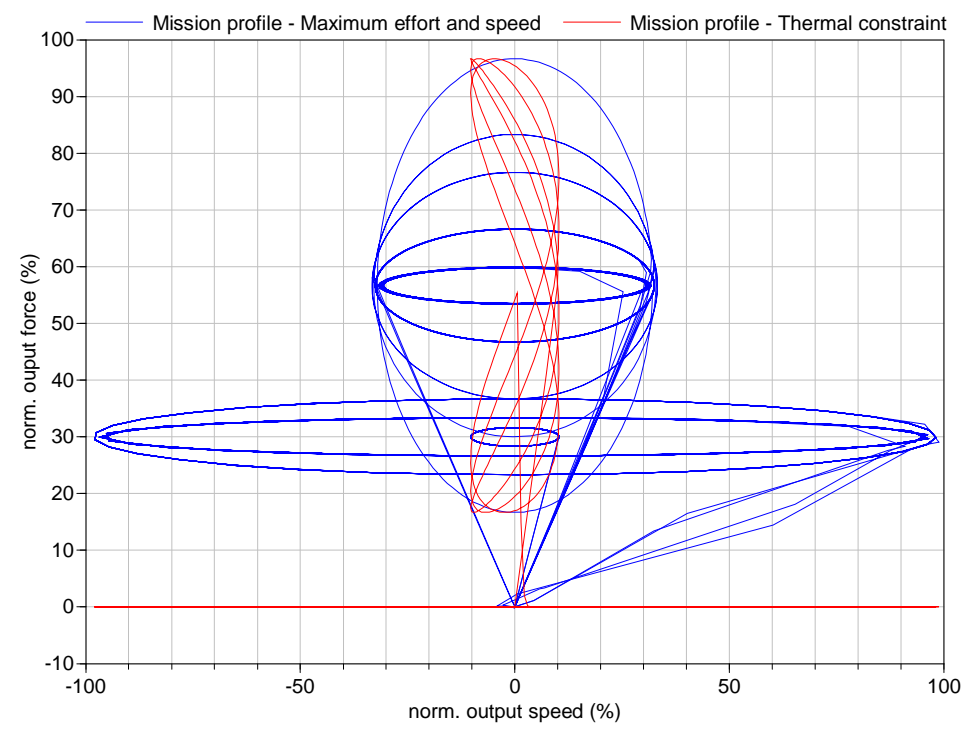

Figure 5: Mechanical (blue) and thermal (red) aileron mission profiles at the actuator output.

\section{2 -Results}

The results obtained by following the sizing methodology described previously are collected in the table of Figure 6. From these results, it is possible to carry out a mass and integration analysis efficiently. In this way the total mass of the actuator is the sum of the component masses returned by the different components models. Figure 6 also includes the component references used by the scaling laws, as well as offthe-shelf components the closest to the scaled ones. It appears clearly that despite the references are often far away from the scaled components (e.g., the nominal torque of the speed reducer reference is more than twenty times that of the scaled one) the scaling laws lead to existing off-the-shelf products accurately.

The comparison between the scaled and off-theshelf actuators illustrates the accuracy of the developed approach. One can notice that the off-the-shelf actuator is a little heavier than the scaled one $(-23 \%)$. This difference of mass is mainly due to the fact that when there is no off-the-shelf component matching exactly the scaled one, then the next bigger component is selected. In the same way, the chosen reducer has a maximum reduction ratio lower than for the scaled one. As a consequence, the electric motor has a more important RMS torque and is bigger. From the dimensions listed, the actuator geometry can be represented within the wing profile to verify its integrability as shown in Figure 6. The maximum length of the actuator is given by the distance between the pivots 1 and 2. Figure 6 shows that mounting all the components in-line does not allow the actuator to fit within these two pivots. A solution consists in mounting the brushless motor and the reducer alongside the roller screw thanks to spur-gears implemented between the reducer output and the rollerscrew input.

In order to take advantage of the developed actuator model, further design explorations could be carried out : effect of varying the length of the crank shaft, evaluating the influence of the actuator lifetime, assessing the interest of an active/active configuration to reduce the mission duty ... 


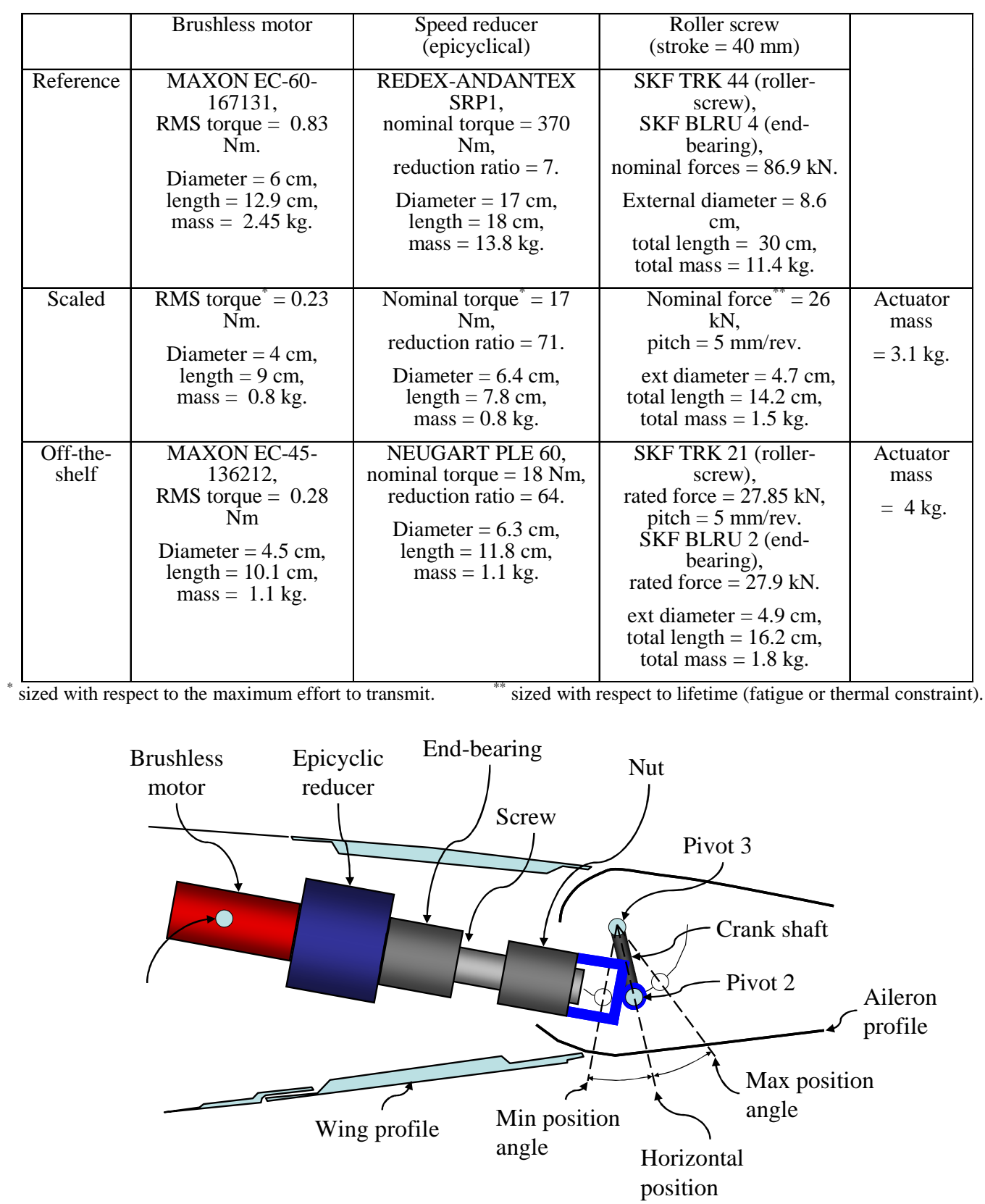

Figure 6: Actuator sizing for a crank shaft length of $45 \mathrm{~mm}$, a component lifetime of 48000 hours and a active/damping configuration (baseline).

\section{Electrical motor design}

\subsection{Electrical actuator design}

The design of an electrical actuator can be undertaken as a step-by-step procedure. It starts with the application requirements that are determine by the previous preliminary design. Then the type of the electrical actuator, that can meet the requirements, has to be chosen. Knowing the type of actuator, its sizes must be determined. This can be achieved by means of a sizing model.

\begin{tabular}{|l|l|}
\hline Symbol (Unit) & Name of quantities \\
\hline Tn $($ N.m) & Nominal torque \\
\hline$\Omega n\left(r a d . s^{-1}\right)$ & Nominal speed \\
\hline Vn (V) & Supply voltage rms value \\
\hline
\end{tabular}

Table I: The main requirements

To illustrate this design procedure, a tool to help engineers to size a permanent magnet brushless dc motor has been developed. This tool is based on analytical models of permanent magnet motor as those proposed in [14][15][16][17]. Analysis of these models show that the sizes of the motor can be obtained 
from only three main requirements among all those obtained from the preliminary design: the nominal torque, the nominal speed and the rms value of the electrical network supplying voltage (Table I). A man of the art approach is then applied to help the users to make different choices. The first choices that the user has to make concern the design choices such as the motor form factor, which is the ratio of the bore diameter to its length, or the mean value of the magnetic field in the gap of the motor (Table II).

\begin{tabular}{|l|l|}
\hline Symbol (Unit) & Name \\
\hline$\lambda$ & $\begin{array}{l}\text { Form factor: the ratio of the bore } \\
\text { diameter } \mathrm{D}(\mathrm{m}) \text { to the length of the } \\
\text { motor L }(\mathrm{m})\end{array}$ \\
\hline $\mathrm{AJ}\left(\mathrm{A}^{2} \cdot \mathrm{m}^{-3}\right)$ & $\begin{array}{l}\text { Product of the electric loading A } \\
\text { to current density } \mathrm{J}\end{array}$ \\
\hline BA $\left(\mathrm{N} \cdot \mathrm{m}^{-2}\right)$ & $\begin{array}{l}\text { Airgap shear stress: product of the } \\
\text { airgap flux density B (T) to the } \\
\text { electric loading A }\end{array}$ \\
\hline $\mathrm{J}\left(\mathrm{A} \cdot \mathrm{m}^{-2}\right)$ & Current density \\
\hline
\end{tabular}

Expert helps are given to users to make these choices straight forward for him. For instance, if the user wants a rather long motor, he chooses a form factor less than one.

\begin{tabular}{|l|l|}
\hline Name & Typical values \\
\hline Form factor & $\begin{array}{l}\text { Long motor }(<1), \text { squared motor } \\
(=1), \text { flat motor }(>1)\end{array}$ \\
\hline Product AJ & $\begin{array}{l}\text { Cooled by natural convection about } \\
10^{10} \mathrm{~A}^{2} \mathrm{~m}^{-3}, \\
\text { Cooled by air forced convection } \\
\text { about } 10^{11} \mathrm{~A}^{2} \mathrm{~m}^{-3}\end{array}$ \\
& $\begin{array}{l}\text { Cooled by liquid forced convection } \\
>10^{12} \mathrm{~A}^{2} \mathrm{~m}^{-3}\end{array}$ \\
\hline $\begin{array}{l}\text { Airgap shear- } \\
\text { stress }\left(\mathrm{Nm}^{-2}\right)\end{array}$ & $\begin{array}{l}\text { Cooled by natural convection and } \\
\text { totally enclosed motor: 3500 - } \\
7000 ;\end{array}$ \\
& $\begin{array}{l}\text { High performance motor magne- } \\
\text { tized by rare earth or NdFeB mag- } \\
\text { nets: } 7000-21000 ; \\
\text { Liquid cooled motor: 70000 - } \\
105000\end{array}$ \\
\hline $\begin{array}{l}\text { Current density } \\
(\text { Am }\end{array}$ & $\begin{array}{l}\text { Totally enclosed motor and cooled } \\
\text { by natural convection: }<510^{6} ; \\
\text { Cooled by air forced convection: } 5 \\
-1010^{6} ; \\
\text { Liquid cooled motor: } 10-5010^{6}\end{array}$ \\
\hline
\end{tabular}

Table III: Example of extpert help for the design choice

From the torque requirement (Table I) and the choice of the quantities in Table II, the bore diameter and the length of the motor can be calculated:

$$
\mathrm{D}=2 . \sqrt[3]{\frac{\lambda \mathrm{Tn}}{4 \pi \mathrm{BA}}} \quad \mathrm{L}=\frac{\mathrm{D}}{\lambda}
$$

Six other choices must be made by the users. Among them are the choices of the permanent magnet and of the magnetic material [18] [19]. The choice of magnetic material for instance is determined by the desired mean values of the magnetic flux density in the magnetic circuit of the motor: the teeth and the yokes of the motor[15][16].

This man of the art approach is done in Modelica by the use of Blocks, modeling the different choices of the users, and connected to each other. In each Block, the equation section allows by reversing the direct analytical sizing model to determine the appropriate geometrical parameter of the motor. For instance, the expression of the torque in the direct model is reverse in the 'Block Design_Choice' to compute the diameter bore and the length of the motor (5). So, these Blocks, modeling the requirements and the choices made by the user, determine the geometrical, physical and structural parameters of the motor. The table IV gives the list of the parameters that can be computed at this stage:

\begin{tabular}{|l|l|}
\hline Symbol (Unit) & $\begin{array}{l}\text { Names of the calculated } \\
\text { quantities }\end{array}$ \\
\hline D (m) & Bore diameter \\
\hline L $(m)$ & Stack length \\
\hline Egap (m) & Airgap thickness \\
\hline Eai $(m)$ & Magnet thickness \\
\hline Ecs $(m)$ & Stator yoke thickness \\
\hline Ecr $(m)$ & Rotor yoke thickness \\
\hline Ns & Turn number of each phase \\
\hline Ws $(m)$ & Slot with \\
\hline Ds $(m)$ & Slot depth \\
\hline Nenc & Number of slots \\
\hline
\end{tabular}

Table IV: The main quantities calculated

In a second part, these blocks are connected to two more Blocks. The first calculates the masses, the volumes and the inertia of the rotor and the second the different losses in the motor such as the winding losses [18] [16].

\subsection{Electrical actuator model library}

In a last Block the electrical parameters of the motor such as the no-load flux, the cyclic inductance and the resistance of each phase. This 'Block Electrical_Parameters' can be connected to a Modelica user model that simulates the dynamic behavior of the motor. In order to help the user to make this kind of Modelica model a library based on lumped parame- 
ters model of electrical motors has been developed [20]. In this model the motor can have nonsinusoidal wave forms. With this library a user can simulate a variable speed motor fed by a PWM controlled voltage. Examples of simulation results are shown on figure 6 and figure 7. These results are obtained from a Modelica program that runs in an AMESIM environment.

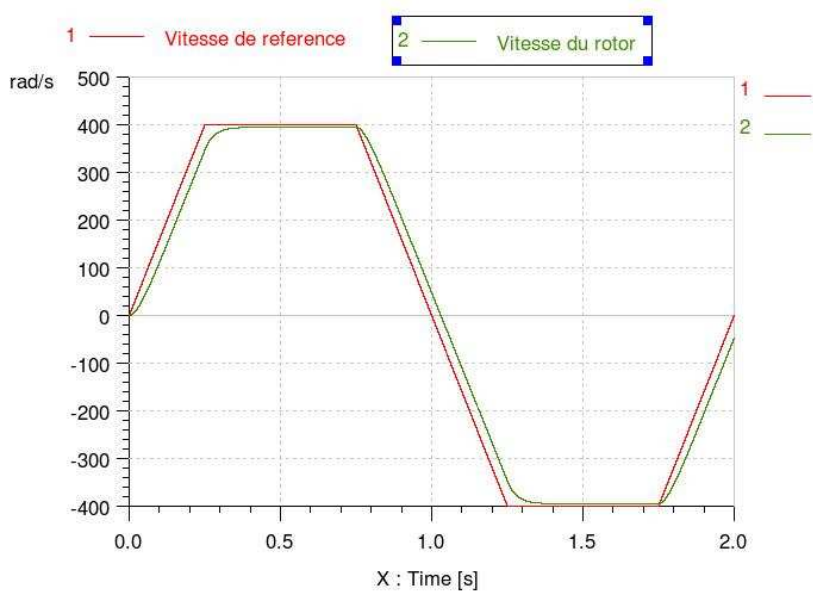

Figure 7: Simulation of trapezoidal speed cycle operation of a motor under design: reference speed and rotor speed

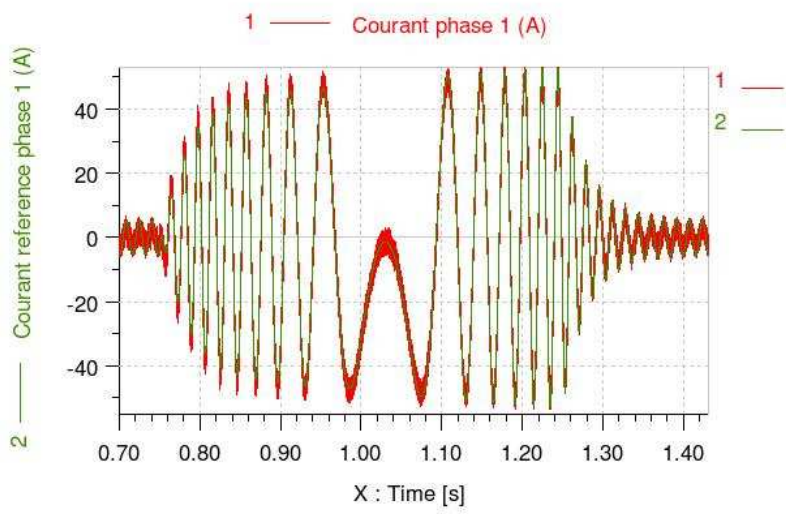

Figure 8: Simulation of trapezoidal speed cycle operation of a motor under design: reference current and current in a phase of the motor.

\section{Detailed design of an aileron brush- less motor}

In this last section, the detailed sizing of a permanent magnet that meets of the requirements of the scaled motor presented in figure 6 is undertaken. The requirements of the projected motor are the following: nominal torque $(\mathrm{Tn}=0.23 \mathrm{~N} . \mathrm{m})$, nominal speed $(\mathrm{Nn}=10000 \mathrm{rev} / \mathrm{mn})$, DC supply $(\mathrm{U}=48 \mathrm{~V})$. The solution is inspired by the Maxon motor (EC45-136212). The following general design choices have been made: product $\mathrm{AJ}$ of $2.10^{11} \mathrm{~A}^{2} \mathrm{~m}^{-3}$, form factor 1 of : 0.4 ;

The chosen AJ product is very high. This value has been determined after many tries with the step by step procedure described in section 4 . We are trying to find a set of dimensions that suits the structure of a slotless motor as suggested by the Maxon motor solution (Figure 6). This AJ product has been chosen with a very low airgap flux density $(0.1 \mathrm{~T})$ in order to be able to put the winding between the stator yoke and the magnet. Besides these choice, a shear stress of one thousand N.m ${ }^{-2}$ is adopted which is very low according to the experts typical value of Table III. Again these values are obtained after running many times our sizing procedure. With the sizing procedure proposed, we find a motor whose main parameters are reported on table $\mathrm{V}$.

\begin{tabular}{|l|l|l|}
\hline $\begin{array}{l}\text { Value of some } \\
\text { chosen and } \\
\text { calculated pa- } \\
\text { rameters }\end{array}$ & Name & $\begin{array}{l}\text { Status (chosen or } \\
\text { calculated) }\end{array}$ \\
\hline $\mathrm{p}=1$ & $\begin{array}{l}\text { Number of pole } \\
\text { pairs }\end{array}$ & chosen \\
\hline $\mathrm{q}=3$ & $\begin{array}{l}\text { Number of } \\
\text { phases }\end{array}$ & chosen \\
\hline$\beta=0.667$ & Rate of pole arc & chosen \\
\hline $\mathrm{D}=0.019 \mathrm{~m}$ & Bore diameter & calculated \\
\hline $\mathrm{L}=0.097 \mathrm{~m}$ & Stack length & calculated \\
\hline $\mathrm{g}=0.97 \mathrm{~mm}$ & Airgap length & calculated \\
\hline $\mathrm{Ns}=38$ & Number of turns & calculated \\
\hline $\mathrm{I}=6.49 \mathrm{~A}$ & Current & calculated \\
\hline $\mathrm{D}_{2}=0.045 \mathrm{~m}$ & Diameter & calculated \\
\hline $\mathrm{P}_{\mathrm{j}}=71 \mathrm{~W}$ & Joule loss & calculated \\
\hline $\mathrm{R}_{\mathrm{LL}}=1.68 \mathrm{~W}$ & $\begin{array}{l}\text { Resistance phase } \\
\text { to phase }\end{array}$ & calculated \\
\hline $\mathrm{L}_{\mathrm{LL}}=0.131 \mathrm{H}$ & $\begin{array}{l}\text { Inductance phase } \\
\text { to phase }\end{array}$ & calculated \\
\hline$\eta=0.77$ & $\begin{array}{l}\text { Efficiency } \\
\text { materials } \\
\text { magnet, copper) }\end{array}$ & calculated \\
\hline $\mathrm{M}=0.41 \mathrm{~kg} \mathrm{calculated}$ \\
\hline
\end{tabular}

Table V: Main parameters of the sized motor

The main drawback of this motor is that the stack length is already greater than the required length on figure 6 . The mass is half of the required mass, but it includes only active materials. The resistance is very high and the efficiency is relatively low. Except the length, all the parameters fit the requirement and are in accordance of the motor proposed by Maxon.

Table $\mathrm{V}$ shows that the scaled motor defined in Figure 6 can be found. This last section show what can 
be obtained from the detailed sizing procedure. One of the use of this procedure is the training of future motor designers. Such a procedure will give them the 'physical sense' that helps to design a motor.

\section{Conclusions}

The approach presented in this paper aims at improving the preliminary design and detailed design on the basis of an efficient sizing and rapid virtual prototyping.

For the preliminary sizing the keystone of this proposed approach is a uniform modelling of the components based on scaling laws that allows having a limited number of input parameters. Using scaling laws developed from the main physical constraints of the components makes the sizing representative of the state-of-the-art of technology. Moreover, it does not require a database or a large amount of data that are cumbersome to build and to maintain, but single component references only. The example has shown how the use of the developed library allows a fast modelling which can be useful for an exploration of different design configurations (active/damping, active/active) and design parameters (crank shaft length and lifetime) and thus supports well taking technical decisions early in the preliminary design by providing a rich insight into the design problematic in an efficient way.

For the detailed design of brushless motors, the man of the art approach presented in this paper to design an electromechanical actuator can be very useful to design quickly a motor 'by hand'. The user controls at each step the effect of his choices on the performances of the motor. The example treated shows that it can be used to find non obvious solution with the help of a preliminary design method based of scaled laws. The results of this preliminary design forced to attempt non obvious choices different from those given by experts guide.

\section{References}

[1] T. Ford, "More-electric aircraft," Emerald, vol. $77,2005$.

[2] F. Roos, "Towards a methodology for inte-grated design of mechatronic servo systems," Text, KTH, Machine Design, 2007.

[3] Linear Motioneering, Danaher Motion, .

[4] ServoSoft, ControlEng, .

[5] Cymex - Alpha, WITTENSTEIN formerly alpha gear drives, .
[6] Jardin, Audrey, Marquis-Favre, Wilfrid, Thomasset, Daniel, Guillemard, Franck, et Lorenz, Francis, "Study of a Sizing Methodology and a Modelica Code Generator for the Bond Graph Tool MS1," University of Applied Sciences, Bielefeld, Germany: 2008, pp. 125-134.

[7] P. Fritzson et V. Engelson, "Modelica - A unified object-oriented language for system model-ing and simulation," ECOOP'98 — Object-Oriented Programming, 1998, pp. 67-90.

[8] H. Elmqvist, D. Ab, S.E. Mattsson, et M. Ot-ter, "Modelica: The new object-oriented modeling language," presented at The 12th European Simu-lation Multiconference," In Proceedings of The 12th European Simulation Multiconference, 1998, pp. 127--131.

[9] P. Minotti et A. Ferreira, Les micromachines , Paris: Hermès, 1998.

[10] G. Spinnler, Conception des machines : principes et applications. 3, Dimensionnement, Lausanne: Presses polytechniques et universitaires romandes, Paris, 2005.

[11] B. Multon, H. Ben Ahmed, M. Ruellan, et G. Robin, "Comparaison du couple massique de di-verses architectures de machines tournantes syn-chrones à aimants," Société de l'Electricité, de l'Electronique et des Technologies de l'Information et de la Communication (SEE), Paris, FRANCE (1995) (Revue), 2006, pp. 85-93.

[12] M. Jufer, Traite d'électricité vol9 :transducteurs, Presses Polytechniques et Universi-taires Romandes (PPUR), 1998.

[13] "Brushless DC Motors," On line ed, Maxon, Ed., 2009, http://www.maxonmotor.com/.

[14] Gordon R. Slemon and Xian Liu, "Modeling and Design Optimization of Permanent Magnet Motors", Electric Machines and Power Systems, 20:71-92, 1992.

[15] J. R. Hendershot Jr and T. J. E. Miller, "De-sign of Brushless Permanent Magnet Motors", Monographs in Electrical Engineering No. 37, Magma Physics Publishing and Clarendon Press, Oxford, 1994.

[16] Jacek F. Gieras and Mitchell Wing, "Permanent Magnet Motor Technology, Design and Applications", Second Edition, Revised and Expanded, Marcel Dekker Inc., 2002.

[17] E. Fitan, F. Messine, and B. Nogarede, "A general analytical model of electrical permanent magnet machine dedicated to optimal design", COMPEL, 22(4) :1037-1050, 2003.

[18] Gordon R. Slemon and Xian Liu, "Core Losses In Permanent Magnet Motors", IEEE Transaction on Magnetics, vol. 26, No. 5, 1653-1655, September 1990.

[19] T. J. E. Miller, "Brushless Permanent-Magnet and Reluctance Motor Drives", Monographs in Electrical Engineering No. 21, Clarendon Press, Oxford, 1989.

[20] T. Sebastian and G. R. Slemon. Transient modelling and performance of variable speed permanent magnet motors, IEEE Transaction on Magnetics, IA-25(1) :101-107, 1989. 
Proceedings 7th Modelica Conference, Como, Italy, Sep. 20-22, 2009 